\title{
OS IMPACTOS DA INOVATIVIDADE E DA CAPACIDADE TECNOLÓGICA NO CONTEXTO DE EMPRESAS DO SEGMENTO METALMECÂNICO
}

\author{
THE IMPACTS OF INNOVATIVE AND TECHNOLOGICAL CAPACITY \\ IN THE CONTEXT OF COMPANIES OF THE METALMECHANICAL SEGMENT
}

DEONIR DE TONI

Professor de Graduação e Pós-Graduação na Universidade de Caxias do Sul Livre-Docente e Pós-Doutor em Administração pela Universidade de São Paulo Orcid: http://orcid.org/0000-0001-9637-8099 / E-mail: deonirdt@terra.com.br

\section{MÁRCIO JOSÉ MIGLIAVACCA}

Diretor Geral na Rexfort Máquinas Ltda

Bacharel em Engenharia Mecânica e Mestre em Administração pela Universidade de Caxias do Sul Orcid: http://orcid.org/0000-0002-4478-0681 / E-mail: marcio@rexfort.com.br

\section{CARLOS ALBERTO COSTA}

Professor do Programa de Mestrado Profissional em Engenharia Mecânica e do Programa de PósGraduação em Administração (Mestrado e Doutorado) da Universidade de Caxias do Sul

Doutor em Manufacturing Engineering - Loughborough University

Orcid: http://orcid.org/0000-0001-5623-8411 / E-mail: cacosta@ucs.br

\section{GABRIEL SPERANDIO MILAN}

Professor e pesquisador da UNISINOS - Universidade do Vale do Rio dos Sinos PPG em Gestão e Negócios - Mestrado e Doutorado Profissional (Porto Alegre - RS)

PPG em Engenharia de Produção e Sistemas - Mestrado e Doutorado (São Leopoldo - RS)

Pós-Doutor em Administração na área de Marketing - Universidade Federal do Rio Grande do Sul

Orcid: http://orcid.org/0000-0003-3480-2653 / E-mail: gabmilan@terra.com.br

\author{
DEISE TAIANA DE ÁVILA DIAS \\ Universidade de Caxias do Sul \\ Doutora em Administração pela Universidade de Caxias do Sul \\ Oricd: https://orcid.org/0000-0002-8765-8395 / E-mail: deiset.dias@gmail.com \\ Endereço: Rua Francisco Getúlio Vargas, 1130 \\ CEP 95070-560 - Caxias do Sul/RS.
}

\begin{abstract}
RESUMO
O estudo apresenta uma análise dos impactos da inovatividade em novos produtos e da capacidade tecnológica sobre o desempenho de mercado das empresas do segmento metalmecânico de Caxias do Sul e de Bento Gonçalves (RS). A partir de uma pesquisa quantitativa, pelo método survey, foi testado um modelo teórico capaz de integrar as dimensões inovatividade e capacidade tecnológica na busca por um melhor entendimento dos fatores que impactam no desempenho de mercado. A partir de uma amostra com 118 empresas, os dados foram analisados por meio de estatísticas multivariadas, utilizando-se a técnica da Modelagem de Equações Estruturais. Das hipóteses que tratam dos impactos positivos gerados pela inovatividade da empresa sobre o novo produto, sobre a capacidade
\end{abstract}

Data de submissão: 10/05/2019. Data de aceite: 15/12/2019. Data de publicação: 20/12/2019. 
tecnológica e sobre o desempenho de mercado, apenas a relação inovatividade e desempenho não possui impacto direto, porém, apresentando relação indireta através do novo produto. Dentre os demais resultados obtidos na pesquisa, a relação entre a capacidade tecnológica e o novo produto não teve suporte estatístico. Entretanto a capacidade tecnológica apresentou impacto positivo sobre o desempenho de mercado. Também foi identificado que a lucratividade modera a relação entre o desenvolvimento de novos produtos (DNP) e o desempenho de mercado das empresas, sendo esta relação mais significativa para empresas com índices maiores de lucratividade. Por fim, foi possível encontrar um coeficiente de explicação de $42,7 \%$ para o desempenho de mercado a partir dos construtos testados no modelo proposto.

Palavras-chave: Novo produto. DNP - desenvolvimento de novos produtos. Inovatividade. Capacidade tecnológica. Desempenho de mercado.

\begin{abstract}
The study presents an analysis of the impact of innovation in new products and technological capacity on the market performance of companies in the metalworking segment of Caxias do Sul and Bento Gonçalves (RS). From a quantitative research, by means the survey method, a theoretical model was tested able to integrate the dimensions of innovation and technological capacity in the search for a better understanding of the factors that impact on market performance. From a sample with 118 companies, the data were analyzed through multivariate statistics, using the Structural Equation Modeling technique. From the hypotheses that deal with the positive impacts generated by the company's innovation on the new product, on technological capacity and on market performance, only the relationship between innovation and performance does not have a direct impact, however, presenting an indirect relationship through the new product. Among the other results obtained in the research, the relationship between technological capacity and the new product was not statistically supported. However, technological capacity had a positive impact on market performance. It has also been identified that profitability moderates the relationship between the development of new products and the market performance of companies, and this relationship is more significant for companies with higher profitability rates. Finally, it was possible to find an explanation coefficient of $42.7 \%$ for the market performance from the constructs tested in the proposed model.
\end{abstract}

Keywords: New product. NPD - new product development. Innovativeness. Technological capability. Market performance.

\title{
1 INTRODUÇÃO
}

O ambiente competitivo organizacional apresenta uma grande velocidade de transformação. Ao observar o cenário globalizado, há movimentos que buscam inserir de forma mais intensa as tecnologias de informação ao meio industrial. Iss opode ser percebido em países como Alemanha, França, Estados Unidos e Espanha. Tais movimentos surgiram do conceito da Indústria 4.0 que nasceu com o objetivo de fortalecer a competitividade do setor de manufatura na Alemanha, por meio da convergência entre a produção industrial e as tecnologias de informação (KAGERMANN et al., 2013). No Brasil, o tema Indústria 4.0 vem ganhando força através de feiras especializadas em segmentos industriais. Esta tendência 
utiliza tecnologias como automação industrial, conectividade contínua e robótica inteligente, que visão melhorar a produtividade dos sistemas industriais de fabricação (POSADA et al., 2015).

Goedhuysa e Veugelersb (2012) ressaltam a complexidade para geração de novos produtos e da necessidade de domínio de novas tecnologias, reforçada pelo movimento de adoção do conceito de indústria 4.0. Assim, se faz necessário que a empresa apresente capacidade tecnológica para tal função. A capacidade tecnológica está relacionada a habilidades e conhecimentos que possibilitam promover mudanças e desenvolver respostas ao ambiente externo competitivo. Ela representa a capacidade da empresa, com base nos conhecimentos acumulados, de desenvolver ações cujo resultado é manter em funcionamento os sistemas atuais e gerar novos produtos e processos.

Quanto maior forem a inovatividade da empresa, os investimentos em capacidade tecnológica e a geração de novos produtos, melhor será, em tese, o desempenho das empresas (seja ele medido por resultado financeiro ou por fatores mercadológicos), conforme indicado por Engelen et al. (2015) e Zoogah (2018). Após a definição e as interações entre os temas abordados nesta pesquisa foram construídas um modelo teórico que propoe um conjunto de seis hipóteses que foram embasadas por referências teóricas e posteriormente postas à prova, através do método de modelagem de equações estruturais.

$\mathrm{Na}$ busca de atender ao objetivo de identificar os impactos da inovatividade e da capacidade tecnológica sobre o novo produto e o desempenho de mercado, foi implementada uma pesquisa de cunho quantitativo-descritivo (HAIR Jr. et al., 2010). O trabalho foi realizado em um ambiente que possui mais de 2.200 organizações, atuantes no setor metalmecânico, nas duas principais cidades da Serra Gaúcha, no caso, Caxias do Sul e o de Bento Gonçalves, onde a maior parte das empresas não é do tipo capital aberto.

Baseado nesse cenário foi definido a seguinte questão de pesquisa: quais os impactos gerados pela inovatividade e pela capacidade tecnológica no novo produto e no desempenho de mercado das empresas do segmento metalmecânico? O objetivo geral deste estudo é identificar a relação entre a inovatividade, a capacidade tecnológica e o novo produto sobre o desempenho de mercado de empresas do setor metalmecânico.

A partir de uma amostra de 118 empresas os resultados indicam que o modelo proposto se mostrou coerente com a base teórica. Cabe destacar que a partir das oito hipóteses apresentadas, seis foram confirmadas. Mostrando que: a inovatividade tem impacto positivo no desenvolvimento de novos produtos $\left(\mathrm{H}_{1}\right)$; a inovatividade tem impacto positivo na capacidade tecnológica das empresas $\left(\mathrm{H}_{3}\right)$; o DNP - Desenvolvimento de Novos Produtos tem impacto positivo no desempenho de mercado das empresas $\left(\mathrm{H}_{4}\right)$; e a capacidade tecnológica tem impacto positivo no desempenho de mercado das empresas $\left(\mathrm{H}_{6}\right)$.

Assim, dentre as contribuições deste estudo, destacam-se a identificação de fatores que impactam de forma direta no desempenho como é o caso do desenvolvimento de novos produtos e a capacidade tecnológica e os fatores que possuem um impacto indireto tais como a inovatividade. Outro achado importante foi a identificação da moderação do nível de lucratividade. Empresas com um maior nível de lucratividade possuem uma relação mais forte entre o desenvolvimento de novos produtos e o desempenho de mercado. Tais achados de pesquisa são importantes, uma vez que ajudam as organizações a melhor direcionar suas estratégias, ações e investimentos no que diz respeito a busca pela inovação e uma maior capacidade tecnológica. 


\section{REFERENCIAL TEÓRICO}

A elaboração do referencial teórico é essencial, sabendo-se que ele clarifica a lógica de construção do objeto de pesquisa, norteando a definição de categorias e os construtos. Também, proporciona suporte às relações prévias das hipóteses e fundamenta o instrumento que auxiliará na interpretação dos resultados da investigação. Desta forma, nas próximas seções está apresentado o referencial teórico deste estudo, trazendo seus construtos e hipóteses de pesquisa.

\subsection{DNP - DESENVOLVIMENTO DE NOVOS PRODUTOS}

Produto pode ser definido, conforme Takahashi e Takahashi (2007), como o resultado do grau de eficiência de uma empresa ou aquilo que ela produz, dando existência ao seu retorno econômico ou ao produto básico, produto e/ou serviço. Todavia, a segunda definição "produto básico" a base a certa do novo produto que será discutida. Em geral, um novo produto pode ser definido pela perspectiva da empresa ou do cliente, pontos que originam diferentes conceitos. O desenvolvimento de um novo produto para Crawford (1997) é toda ação, geração de conceito, avaliação do plano de produto e de marketing e comercialização destinado à implementação de uma nova oferta.

Rosenfeld et al. (2006) destacam que, o desenvolvimento de novos produtos é um processo de negócio cada vez mais crítico devido à internacionalização dos mercados, ao aumento da diversidade de produtos e à redução do seu ciclo de vida, sendo assim novos produtos buscam atender segmentos específicos de mercado, incorporando novas tecnologias e se adequando a novos padrões e restrições legais. Goedhuysa e Veugelersb (2012) reforçam o pensamento de Rosenfeld et al. (2006), ao enfatizar que o desenvolvimento de um novo produto é complexo, exige da organização aquisição (máquinas e equipamentos) e domínio de novas tecnologias, de forma independente ou combinada com a estratégia de desenvolvimento tecnológico.

Quanto à classificação de novo produto, Sheng, Zhou e Lessassy (2013), ao estudar empresas de alta tecnologia na China, classificaram o tema utilizando os termos: (i) originalidade; (ii) radicalidade; e (iii) singularidade. Em relação à interpretação do cliente sobre o novo produto, Verganti e Öberg (2013) afirmam que, mesmo nos mercados industriais, as empresas vão além da melhoria do desempenho funcional para o desenvolvimento de um novo produto: há um avanço na abordagem em profundidade da razão pela qual seus clientes compram e usam um produto, o que chamaram de inovação radical de significados de produtos.

Identifica-se, com base na análise da abordagem dos vários autores pesquisados que discutem o tema novo produto, que o conceito representa, fundamentalmente, uma nova oferta que será comercializada por uma empresa. Dessa forma, entende-se que novo produto é toda a nova oferta que será entregue ao mercado, indiferente da intensidade de mudança tecnológica embarcada ou percebida pelo cliente, desenvolvida com base nas habilidades tecnológicas que a empresa possui. $\mathrm{E}$ isto tende a repercutir como resultado a manutenção competitiva da organização ou mesmo o distanciamento da concorrência, a fim de obtenção de resultados superiores no desempenho da empresa.

\subsection{INOVATIVIDADE}

Em um estudo realizado por Subramanian (1996), ele apresenta inovatividade como um construto multidimensional, composto de três dimensões: o processo de adoção de 
inovação, o ambiente externo e o desempenho organizacional, constatando que: (i) qualquer medida válida de inovatividade deve ser baseada na adoção de diversas inovações; (ii) além do número de inovações adotadas, o tempo de aprovação de cada inovação também deve ser considerado; e (iii) a consistência dos padrões de adoção por mais tempo também deve ser medida.

Em relação à dimensão ambiente externo proposta por Subramanian (1996), a percepção da inovatividade das organizações pode ser maior em um país do que em outro. Wang e Ahmed (2004) tratam a inovatividade como a capacidade de inovação global da organização de inserir novos produtos no mercado ou mesmo de abrir novos mercados, utilizando-se da orientação estratégica, do comportamento inovador e o processo. Sob esta orientação, para os autores, cinco dimensões determinam uma inovatividade global da organização: (i) inovatividade de produto; (ii) inovatividade de mercado; (iii) inovatividade de processo; (iv) inovatividade comportamental; e (v) inovatividade estratégica.

Os resultados da pesquisa de Ganzer et al. (2016) retomam a definição de inovatividade proposto pelos autores Bezerra (2011) e Poteralski (2011) ao confirmar ela como uma capacidade da empresa em estar em constante atualização, lançando novos produtos com frequência, renovando maquinário de produção e mantendo a prática de incentivo de novas ideias. Com base na análise da abordagem dos autores pesquisados observa-se que empresas que possuem interesse em adotar uma inovação mais cedo que as outras, aliando um processo de aprendizagem que favoreça participar e apoiar novas ideias.

Desta forma, entende-se inovatividade como um recurso que a empresa possui de gerar novos conhecimentos, advindos de um comportamento duradouro pautado na aspiração de mudança e na busca por se diferenciar da concorrência, os quais podem gerar como resultado novos produtos e processos, possibilitando através da medida de geração de tais resultados em comparação com os de seus concorrentes, mensurar o grau de inovatividade da empresa. Tais resultados objetivam sustentar a sobrevivência e/ou gerar incrementos positivos no desempenho da empresa. Desta forma, é apresentada a seguinte hipótese de pesquisa:

H1: A inovatividade tem impacto positivo no desenvolvimento de novos produtos.

\subsection{CAPACIDADE TECNOLÓGICA}

As capacidades da empresa estão relacionadas à Visão Baseada em Recursos (RBV Resource Based-view), considera-se um recurso vital, que as empresas devem cultivar para alcançar um desempenho superior (BARNEY, 1991). Quando relacionados os temas de RBV com capacidades, Teece, Pisano e Shuen (1997) saem do ambiente estático para o ambiente de mudança, e definem capacidades dinâmicas como a habilidade da empresa de integrar, construir e reconfigurar competências internas e externas para lidar com ambientes que sofrem alteração frequentemente.

Neste sentido, Ensiernhardt e Martin (2000) destacam as capacidades dinâmicas como um enriquecimento da RBV. Uma das justificativas para a necessidade de ampliação do posicionamento da RBV está relacionada ao fato de a mesma não possuir uma adaptabilidade a ambientes de rápida mutação e/ou incertos. Inclusive, Miranda e Figueiredo (2010, p. 80) argumentam que o conceito de capacidades dinâmicas está vinculado aos "recursos necessários para gerar e gerenciar atividades inovadoras em produtos, processos e organização da produção, sistemas organizacionais, equipamentos e engenharia de projetos; em outras palavras, mudança tecnológica".

Dessa forma, identifica-se que a capacidade dinâmica é uma competência interna da 
empresa, a qual tem a finalidade de conquistar melhores resultados, também é associada à percepção apurada sobre as nuances ambientais, dentre as quais desta-se a capacidade tecnológica. Lall (1992) definiu a capacidade tecnológica como um esforço interno, para dominar e adaptar as condições locais às novas tecnologias. Logo, a capacidade tecnológica é vista como uma vertente da capacidade dinâmica que tem sido explorada por tomadores de decisões de diferentes segmentos e tamanhos de empresas como possível potencializadora de estratégias em função das incertezas ambientais.

Bell e Pavitt (1995) incluem na teoria de capacidade tecnológica, características como habilidades, conhecimentos e experiências para manter sistemas atuais em funcionamento e para gerar mudanças técnicas. Ao pesquisar empresas de sistemas de informações taiwanesas, Hsu et al. (2014) encontraram que o acúmulo de conhecimento fortalece não só a capacidade tecnológica de uma empresa, mas também seu alinhamento com sua capacidade de comercialização, que, por sua vez, melhora o desempenho do novo produto no mercado afetando dessa forma o desempenho da empresa de maneira positiva.

Além disso, Tzokas, Kim e Akbar (2015) identificaram em sua pesquisa que a capacidade tecnológica possui uma relação com o desempenho geral da empresa, e esta relação é mediada pela capacidade de absorção do conhecimento pela empresa e alocação deste no desenvolvimento e lançamento de suas ofertas no mercado. Portanto, entende-se que capacidade tecnológica é a habilidade que a empresa tem, a partir de conhecimentos acumulados, de desenvolver ações realizadas por pessoas de competências distintas, utilizando e aplicando tal conhecimento, cujo resultado é manter em funcionamento os sistemas atuais e gerar novos produtos e processos. Resultados estes que possuem o objetivo de gerar mudanças que melhorem o desempenho econômico da empresa. Dessa forma, emerge a segunda hipótese de pesquisa:

H2: A capacidade tecnológica tem impacto positivo no DNP - Desenvolvimento de Novos Produtos.

Poteralski (2011) reúne os conceitos de inovatividade de Lumpkin e Dess (1996), Calantone, Cavusgil e Zhao (2002), Rogers (2003) e Wang e Ahmed (2004), quando descreve seu entendimento de inovatividade como sendo a capacidade e a motivação de procurar e colocar em prática inovações científicas, novos conceitos, ideias e invenções, gerando soluções inovadoras que se manifestam como melhorias da inovação de uma empresa.

Tal capacidade de inovação é uma questão de sobrevivência para as organizações na atual competição de mercado. Onde as inovações geram diferenciação levando a um distanciamento da concorrência, tornando obsoleta a empresa que não for capaz de se reinventar, mudar mais rápido que seu concorrente e encontrar novos recursos antes que os atuais acabem (BEZERRA, 2011). Dessa forma, as empresas que têm alta capacidade de inovar, são suscetíveis a terem mais inovação indiferente de seu tamanho (MENGUC; AUH, 2006).

É possível, também, uma análise relacionando inovatividade e capacidade tecnológica através do entendimento de ambas, obtido com base nos autores pesquisados, onde as duas possuem como característica o conhecimento, sendo a inovatividade entendida como um recurso da empresa que possibilita gerar novos conhecimentos, advindos de um comportamento pautado na aspiração de mudança (DIBRELL; CRAIG; HANSEN, 2011). Por sua vez, o conhecimento gerado pode ser aproveitado pela firma através de sua capacidade tecnológica, já que é entendida como a habilidade de utilizar e aplicar conhecimentos para gerir sistemas atuais e gerar mudanças (DOTZEL et al., 2013). Desta forma, é apresentada a seguinte hipótese:

H3: A inovatividade tem impacto positivo na capacidade tecnológica das empresas. 


\subsection{DESEMPENHO DE MERCADO}

Ao abordar o desempenho, Venkatraman e Ramanujam (1986), baseiam-se no uso de medidas percebidas para operacionalizar o tema, em termos de duas dimensões, a saber, financeira e de mercado. O desempenho é tratado pelos autores como um fenômeno bidimensional, onde o desempenho financeiro reflete as rendas econômicas internas para a empresa decorrentes de suas atividades estratégicas e o desempenho do mercado às relações da empresa com o mercado que ela atua. Spanos e Lioukas (2001), por sua vez, concluem, com base em vários estudos empíricos, que o desempenho de mercado afeta de forma positiva e, com frequência, a rentabilidade da empresa, também o inverso é verdadeiro segundo suas análises.

Neste sentido, Homburg e Jensen (2007) indicam que o desempenho de mercado se refere à medida em que a empresa atinge melhores resultados relacionados ao mercado, do que seus concorrentes, em relação a métricas, como reações rápidas a oportunidades de mercado, satisfação e lealdade do cliente bem como a aquisição de novos clientes.

As empresas podem manter seu poder de mercado ao longo do tempo, através de um fluxo contínuo de inovações e transformar ganhos temporários de um único novo produto em desempenho contínuo e superior, com múltiplas introduções de novos produtos. Sendo assim, o novo produto contribui positivamente para o desempenho da empresa, atenuando as forças naturais da concorrência ou mudanças nos padrões de consumo que tendem a dissipar retornos superiores ao longo do tempo (RUBERA; KIRCA, 2012).

Percebe-se que, apesar de resultados diversos e algumas especificidades, a maioria dos estudos aponta, de uma forma ou outra, para a relação positiva entre o novo produto a inovatividade e a capacidade tecnológica com o desempenho de mercado das empresas (GUAN et al., 2006; RUBERA; KIRCA, 2012; SHENG; ZHOU; LESSASSY, 2013). Estas constatações reforçam o pressuposto exposto de que, quanto maior forem a inovatividade da empresa, os investimentos em capacidade tecnológica e a geração de novos produtos, melhor é o desempenho das empresas (seja ele medido por resultado financeiro, ou fatores mercadológicos). Por consequinte, foram formuladas as seguintes hipóteses de pesquisa:

H4: O DNP - Desenvolvimento de Novos Produtos tem impacto positivo no desempenho de mercado das empresas.

H5: A inovatividade tem impacto positivo no desempenho de mercado das empresas.

H6: A capacidade tecnológica tem impacto positivo no desempenho de mercado das empresas.

\subsection{O PAPEL MEDIADOR DO DNP - DESENVOLVIMENTO DE NOVOS PRODUTOS E A MEDIAÇÃO- MODERAÇÃO DA LUCRATIVIDADE}

Com base na investigação de vários estudos que buscam compreender os fatores que afetam o desempenho de um novo produto, Tidd e Bodley (2002) identificaram elementos de algum consenso nesses estudos, que são: vantagem do produto (benefícios ao cliente), conhecimento do mercado, definição clara do conceito do produto (posicionamento), avaliação do risco, organização para o projeto e mobilização de recursos, competência na execução do projeto e apoio do gestor principal (BOEHE; MILAN; DE TONI, 2009).

Para Cooper (1996), o desempenho de um novo produto está associado a três fatores principais: o processo, os recursos e as estratégias. Desse modo, a inovação de uma empresa é fortemente influenciada por suas estratégias e pela disponibilidade de recursos e habilidades presentes em sua equipe de trabalho. Cooper, Edgett e Kleinschmidt (2004) 
verificaram que muitas das melhores práticas no processo de DNP estão diretamente associadas à cultura e ao clima organizacionais, voltados à inovação, à equipe envolvida diretamente com a inovação de produtos e ao papel do gestor sênior do projeto.

Por isso, a criação e entrega de um valor superior de um produto ou serviço e consequentemente uma maior lucratividade pode ocorrer por meio de três importantes ações: (i) excelência operacional (ex.: baixo custo); (ii) intimidade com o cliente (ex. customização); e (iii) liderança no produto (ex.: inovação) (GUO et al., 2018). Em decorrência disso, observa-se que uma empresa, ao adotar uma estratégia de inovação, pode aumentar o desempenho com seus novos produtos (COOPER; KLEINSCHMIDT, 1987). Sendo assim, a adoção de uma estratégia de inovação é positivamente relacionada a um melhor desempenho no desenvolvimento de novos produtos (DE TONI; MILAN; REGINATO, 2011).

Um melhor desempenho em novos produtos pode advir da combinação entre recursos, capacidades e habilidades existentes na empresa (SONG; PARRY, 1997; VERONA, 1999). Logo empresas com maiores recursos, portanto com maior lucratividade conseguem investir mais e melhor no desenvolvimento de novos produtos. Portanto a alocação de recursos, então, pode levar a uma maior vantagem no lançamento de um produto diferenciado, com maior qualidade, que seja inovador ou que melhor satisfaça as expectativas dos clientes (SONG; PARRY, 1997). Sendo assim, a alocação de recursos para atividades de desenvolvimento de novos produtos é positivamente relacionada ao desempenho das organizações (DE TONI et al., 2011).

Neste contexto, é possível verificar que empresas mais lucrativas conseguem investir mais em novos produtos e, consequentemente, ter um melhor desempenho de mercado. Portanto, a lucratividade pode ser um importante moderador da relação entre o desenvolvimento de novos produtos e o desempenho de mercado das empresas (DAMANPOUR; WISCHNEVSKY, 2010). Consoante isso, é possível apresentar a sétima hipótese de pesquisa.

H7: A capacidade de DNP - Desenvolvimento de Novos Produtos, com níveis de lucratividade alta, demostra um maior efeito direto sobre o desempenho de mercado das empresas; enquanto para níveis baixos de lucratividade não haverá diferença significativa.

Para facilitar a compreensãor acerca do Modelo Teórico proposto e das suas respectivas hipóteses de pesquisa, segue a Figura 1.

Figura 1 - Modelo Teórico Proposto e Hipóteses de Pesquisa

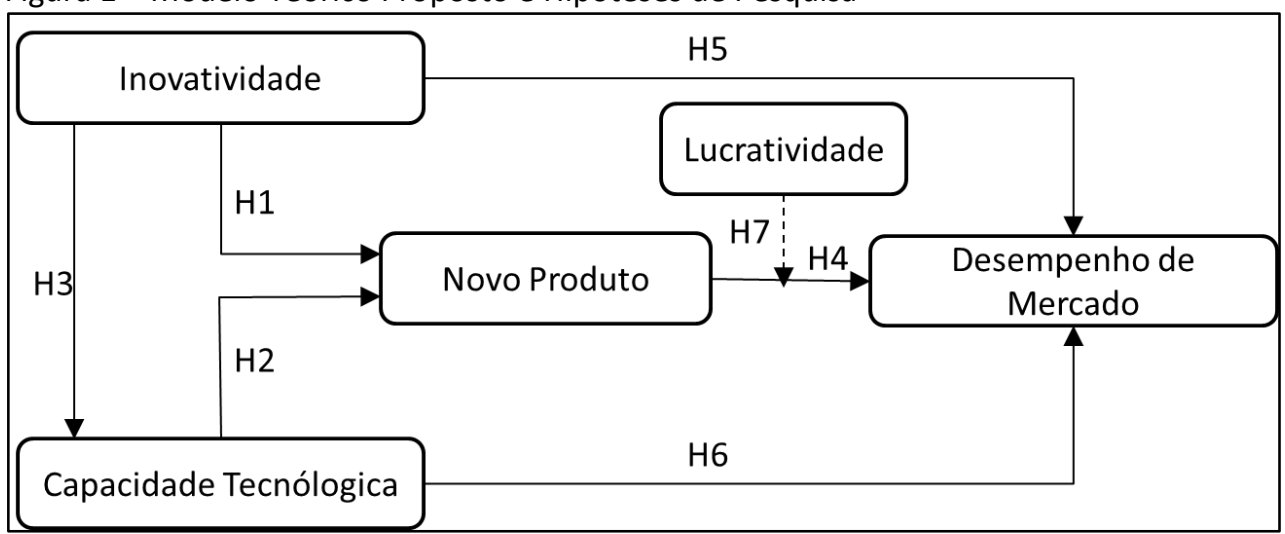

Fonte: Elaborada pelos autores (2019).

Na próxima seção, é apresentado o método de pesquisa. Onde está abordada a população e amostra final desta investigação. Destaca-se, também, a composição do instrumento de coleta de dados, bem como a realização do teste piloto. 


\section{MÉTODO DE PESQUISA}

Esta investigação foi definida como uma pesquisa descritiva, de natureza quantitativa. A amostra foi definida por conveniência e não probabilística, sendo que os dados foram coletados por meio de um questionário. Em relação ao construto novo produto foi utilizado o instrumento original de Darroch (2005), com a tradução reversa de Ganzer (2017). O instrumento de pesquisa para medir o construto inovatividade é proveniente da escala original de Calantone, Cavusgil e Zhao (2002) e Wang e Ahmed (2004), feito tradução reversa por Ganzer (2017). Para mensurar a capacidade tecnológica, foi utilizado o original de Tzokas, Kim e Akbar (2015), traduzido por Panizzon (2016). E, por fim, para o desempenho de mercado das empresas, as questões utilizadas foram as originais de Pfeffer (2005) e De Toni, Milan e Schuler (2009). A escala utilizada pode ser visualizada no Apêndice A.

As variáveis do instrumento de pesquisa totalizaram 26 questões, com escala do tipo Likert de sete pontos. O instrumento foi composto por oito variáveis de desenvolvimento de novos produtos, oito variáveis de inovatividade, quatro variáveis para capacidade tecnológica e sete variáveis para o desempenho de mercado. Após aplicação de teste piloto, o total de variáveis foi mantido. A qualificação do questionário foi administrada em dois momentos distintos: uma avaliação conduzida por dois especialistas e o teste piloto para verificação do questionário em entrevista com dois respondentes, sendo gestores das empresas.

Como a maioria das empresas pesquisadas não é de capital aberto, portanto, não é obrigada a fornecer demonstrações financeiras, foram utilizadas medidas percebidas para avaliar o desempenho de mercado, com base em uma escala reflexiva estabelecida (SPANOS; LIOUKAS, 2001). Wang e Ang (2004) afirmam, em sua pesquisa, que a maior parte dos trabalhos encontrados por eles utilizam formas de medição de desempenho fundamentadas na percepção dos gestores.

Este estudo foi ambientado no segmento metalmecânico. A população total deste estudo foi estimada em 2.254 organizações, esta informação foi baseada no banco de dados do SIMECS - Sindicato das Indústrias Metalúrgicas, Mecânicas e de Material Elétrico de Caxias do Sul (RS) e do SIMMME - Sindicato das Indústrias Metalúrgicas, Mecânicas e de Material Elétrico de Bento Gonçalves (RS). A coleta dos dados não fez distinção de tamanho de empresa quanto a faturamento.

A partir deste banco de dados foram feitos contatos com as empresas destas duas entidades através de ligações telefônicas e mensagens envidas por e-mail para os responsáveis pelas áreas de inovação ou desenvolvimento de novos produtos. Estes contatos foram realizados durante os meses de novembro e dezembro de 2017, sendo que após várias tentativas para aumentar o número de respondentes, decidiu-se encerrar a coleta de dados em janeiro de 2018. Assim, ao final do processo de coleta de dados, obteve-se uma amostra total de 118 casos válidos.

\section{ANÁLISE E DISCUSSÃO DOS RESULTADOS}

Para análise dos dados válidos foi utilizada a análise fatorial exploratória, a análise fatorial confirmatória e a análise de caminhos (path analysis), por meio da Modelagem de Equações Estruturais. Todas as análises contaram com o auxílio dos softwares Microsoft Office Excel $^{\circledR}$ 2013, Statistical Package for the Social Sciences (SPSS ${ }^{\circledR} 20$ ), Analysis of Moment Structures $\left(\operatorname{Amos}^{\circledR} 20\right)(K L I N E, 2011)$. 


\subsection{PROCEDIMENTO DE ANÁLISE DOS DADOS}

Neste estudo foram analisadas as duas categorias dos dados brutos, as quais são indicadas para uma correta aplicação das técnicas de análise multivariadas, que são: a) a investigação dos dados perdidos ou valores ausentes (missing data ou missing values), assim como das observações atípicas ou dos outliers; e b) as análises direcionadas à distribuição dos dados e relação entre variáveis, incluindo investigações quanto à normalidade, multicolinearidade, linearidade e homocedasticidade desses dados (HAIR Jr. et al., 2009; KLINE, 2011). Foram aplicados os testes, não havendo a necessidade de excluir casos válidos ou respondentes.

Por conseguinte, para de Hair Jr. et al. (2009) e Kline (2011), quatro suposições devem ser compreendidas, já que incidem toda a técnica estatística univariada e multivariada, que são definidas como: normalidade, homoscedasticidade, linearidade e multicolinearidade. Identificou-se que todos os índices ficaram dentro das recomendações da literatura.

\subsection{VALIDAÇÃO INDIVIDUAL DOS CONSTRUTOS}

A validade de um construto é dada pelo grau em que um conjunto de itens medidos realmente reflete o construto latente que se propõem mensurar (HAIR Jr. et al., 2009). Desta forma, antes de validar o modelo completo, com todos os construtos propostos foi realizado a validação individual dos construtos. Para a validação individual dos construtos foram avaliadas a confiabilidade, a validade convergente e a validade discriminante.

Todas as cargas fatoriais padronizadas apresentadas atenderam ao valor mínimo exigido. A confiabilidade composta dos construtos apresentou indicador de validade considerado adequado, conforme a literatura, acima de 0,7. A variância extraída, com excessão da Inovatividade, que ficou abaixo do recomendado $(0,5)$, apresentaram-se superiores ao mínimo indicados pela literatura, confirmando uma boa validade convergente dos construtos.

A validade discriminante se refere à intensidade pela qual determinada escala não se correlaciona com as medidas de outros construtos. Neste estudo, foi realizada uma comparação entre a variância extraída da dimensão e suas variâncias compartilhadas. Os resultados confirmam a validade discriminante, na medida em que as dimensões: variâncias extraídas apresentam-se superiores às compartilhadas (FORNELL; LARCKER, 1981; CHURCHILL Jr., 1999). Os resultados das análises deste método citado estão representados na Tabela 1.

Tabela 1 - Validade discriminante

\begin{tabular}{lcccc}
\hline & $\begin{array}{c}\text { Novo } \\
\text { Produto }\end{array}$ & Inovatividade & $\begin{array}{c}\text { Capacidade } \\
\text { Tecnológica }\end{array}$ & $\begin{array}{c}\text { Desempenho } \\
\text { de Mercado }\end{array}$ \\
\hline Novo Produto & 0,503 & & & \\
Inovatividade & 0,764 & 0,432 & & \\
Capacidade Tecnológica & 0,364 & 0,563 & 0,767 & \\
Desempenho de Mercado & 0,368 & 0,320 & 0,301 & 0,647 \\
\hline
\end{tabular}

Fonte: Dados provenientes da pesquisa.

Para atender à literatura, a variância extraída deve ser superior às compartilhadas (FORNELL; LARCKER, 1981; CHURCHILL Jr., 1999). O resultado da análise da validade discriminante é considerado uma limitação desta pesquisa, não atendendo as especificações da literatura. Ao analisar as questões que compõem os contrutos inovatividade e novo 
produto é possível observar que apresentam alguns pontos semelhantes. Por sua vez, para mensurar o construto novo produto, Wang e Ahmed (2004) se utilizam de uma questão que possui características da inovatividade, tal como comportamento de longo prazo, ao questionar se a empresa em comparação aos seus concorrentes tem apresentado mais produtos inovadores nos últimos cinco anos.

\subsection{RESULTADOS DA PESQUISA}

Com base na implementação de todas as etapas de investigação e dos procedimentos de análise dos dados caracterizados anteriormente, o foco das análises foi concentrado ao aprofundamento das características da amostra em estudo e, especialmente, à avaliação das relações estruturais entre os construtos.

\subsubsection{Caracterização da Amostra}

A pesquisa resultou em uma amostra de 118 respondentes. A predominância de idade dos empreendedores do setor metalmecânico foi entre 30 e 39 anos (45,8\%), com pósgradução completa (40,7\%). É possível observar que a maioria das empresas tem até 19 colaboradores (48,3\%), acima de 20 anos de fundação $(44,9 \%)$ e em relação à importação $(51,7 \%)$ e à exportação $(52,5 \%)$ há um equilíbrio das empresas dado que aproximadamente delas metade realiza tais negociações. Há duas faixas de faturamento das empresas: primeiro $(41,5 \%)$ de empresas entre 360 mil a 3,6 milhões e um segundo $(33,1 \%)$ de empresas que faturam acima de 12 milhões por mês.

Quanto à projeção de vendas para o ano de 2018, a maioria dos empreendedores (50,8\%) estimou que o aumento de vendas em 2018 fosse de até 10\%, quando comparado como ano anterior. Em relação à lucratividade estimada para o ano de 2018 , mais de $50 \%$ dos empreendedores acreditam que a mesma estaria entre 0 a 10.

\subsection{VALIDAÇÃO DO MODELO ESTRUTURAL}

O procedimento do desenvolvimento da validade do modelo estrutural seguiu as diretrizes gerais expostas, com adequação quando necessária dos construtos e a identificação da qualidade dos ajustes (Goodnessof Fit - GOF), uma vez que a validação do modelo estrutural acontece com base na qualidade dos GOFs. Na Tabela 2 estão apresentadas as medidas de ajustes alcançadas com base no método de estimação (ML - Maximum Likelihood ou Máxima Verocimilhança).

Tabela 2 - Índices de Ajuste da AFC - Análise Fatorial Confirmatória dos Construtos

\begin{tabular}{|c|c|c|c|c|}
\hline \multirow[b]{2}{*}{ Índices } & \multicolumn{4}{|c|}{ Construtos Analisados } \\
\hline & Novo Produto & Inovatividade & $\begin{array}{l}\text { Capacidade } \\
\text { Tecnológica }\end{array}$ & $\begin{array}{c}\text { Desempenho } \\
\text { de Mercado }\end{array}$ \\
\hline$\chi 2 / g l(C M I N / D F)(<5)$ & 1,766 & 1,091 & 1,094 & 3,179 \\
\hline $\operatorname{GFI}(>0,9)$ & 0,952 & 0,981 & 0,991 & 0,931 \\
\hline AGFI $(>0,9)$ & 0,888 & 0,933 & 0,956 & 0,819 \\
\hline RMSEA $(0,05$ a 0,08$)$ & 0,081 & 0,028 & 0,028 & 0,136 \\
\hline $\mathrm{NFI}(>0,9)$ & 0,947 & 0,976 & 0,994 & 0,956 \\
\hline TLI $(>0,9)$ & 0,958 & 0,995 & 0,999 & 0,942 \\
\hline $\mathrm{CFI}(>0,9)$ & 0,976 & 0,998 & 1,000 & 0,969 \\
\hline
\end{tabular}

Fonte: Dados provenientes da pesquisa. 
No que se refere ao índice $\chi 2 / g l$ (CMIN/DF) todas as dimensões que atenderam ao valor indicado pela literatura, a qual sugere $<5$. O mesmo aconteceu em relação ao índice GFI, onde todas as dimensões apresentaram resultados superiores ao sugerido na literatura 0,9. Ao observar o índice AGFI, esta investigação indicou que as dimensões que atenderam ao valor indicado foram: Inovatividade e Capacidade Tecnológica. Já o Desempenho não apresentou resultado satisfatório, todavia o construto Novo Produto ficou no nível de fronteira. Para o índice RMSEA, apenas o desenvolvimento de novos produtos apresentou resultado no nível de fronteira, em relação ao especificado na teoria as demais não apresentaram resultado satisfatório. Para o NFI, o TLI e o CFI, todos os coinstrutos atenderam ao valor indicado na literatura que sugere valores superiores a 0,9.

Mediante a análise dos GOFs de cada dimensão e do modelo estrutural, conforme ilustrado na Tabela 2 e na Tabela , percebeu-se que os resultados foram satisfatórios, já que alguns indicadores contemplam e/ou ficaram no nível de fronteirados valores de referências, atendendo as recomendações da literatura, conforme Hair Jr. et al. (2009) e Arbuckle (2009). Cabe ressaltar que embora alguns construtos apresentaram alguns índices fora do recomendado, isso não as invalida sua permanência no modelo, uma vez que Hair Jr. et al. (2009) dizem que a utilização de três ou quatro índices de ajuste proporciona evidências adequadas de ajustes de modelo.

Tabela 3 - Índices de Ajuste do Modelo Estrutural

\begin{tabular}{c|c}
\hline Índices de Ajuste Analisados & Resultados Obtidos \\
\hline$\chi 2 /$ gI (CMIN/DF) (<5) & 1,636 \\
\hline GFI $(>0,9)$ & 0,791 \\
\hline AGFI $(>0,9)$ & 0,738 \\
\hline RMSEA $(0,05$ a 0,08) & 0,074 \\
\hline $\operatorname{NFI}(>0,9)$ & 0,832 \\
\hline $\operatorname{TLI}(>0,9)$ & 0,915 \\
\hline $\operatorname{CFI}(>0,9)$ & 0,926 \\
\hline
\end{tabular}

Fonte: Dados provenientes da pesquisa.

Nos índices analisados para o modelo estrutural, foi possível perceber que os resultados obtidos para o CMIN/DF, RMSEA, TLI e o CFI atendem as indicações da literatura. No entanto, para os índices, $\mathrm{AGFI}, \mathrm{GFI}$, e NFI esta investigação observou que seus resultados ficaram fora da fronteira. Em relação aos índices GFI e AGFI, segundo Bagozzi e Yi (2012), ambos os índices dependem do tamanho da amostra e as simulações mostram que ambos não funcionam bem em comparação aos índices CMIN/DF, RMSEA, NFI e CFI. Portanto, para os autores, os índices mais confiáveis são CMIN/DF, RMSEA, NFI e CFI.

\subsection{TESTE DE HIPÓTESES}

Para testar as hipóteses pertinentes ao modelo teórico proposto, foram analisadas a significância e a amplitude dos coeficientes de regressão estimados. A Tabela 4 tem a finalidade de expor os resultados destes diagnósticos que serão descritos na sequência. 
Tabela 4 - Teste de Hipóteses

\begin{tabular}{ccccccccc}
\hline Hi & \multicolumn{2}{c}{ Relação Causal Testada } & $\begin{array}{c}\text { Estima- } \\
\text { te }\end{array}$ & S.E. & C.R & Sig. & Resultados \\
\hline H1 & INOVAT & $\rightarrow$ & NOV_PROD & 1,252 & 0,270 & 4,641 & $<0,001$ & Suportada \\
H2 & CAP_TECN & $\rightarrow$ & NOV_PROD & $-0,107$ & 0,129 & $-0,826$ & 0,407 & $\begin{array}{c}\text { Não } \\
\text { Suportada }\end{array}$ \\
H3 & INOVAT & $\rightarrow$ & CAP_TECN & 1,098 & 0,187 & 5,875 & $<0,001$ & Suportada \\
H4 & NOV_PROD & $\rightarrow$ & DESEMP_MERC & 0,635 & 0,307 & 2,067 & 0,039 & Suportada \\
H5 & INOVAT & $\rightarrow$ & DESEMP_MERC & $-0,275$ & 0,506 & $-0,543$ & 0,587 & $\begin{array}{c}\text { Não } \\
\text { Suportada }\end{array}$ \\
H6 & CAP_TECN & $\rightarrow$ & DESEMP_MERC & 0,357 & 0,158 & 2,261 & 0,024 & Suportada \\
\hline
\end{tabular}

Fonte: Dados provenientes da pesquisa.

Inicialmente, foram apresentadas as dimensões que impactam no Novo Produto, onde uma das duas hipóteses foi suportada estatisticamente que é $\mathrm{H}_{1}(\beta=1,252, p<0,001)$. Já a hipótese $\mathrm{H}_{2}$ não foi suportada, sendo rejeitada. Em relação à $\mathrm{H}_{3}(\beta=1,098, p<0,001)$, que relaciona a Inovatividade com a Capacidade tecnológica, esta foi suportada estatisticamente.

Por fim, são apresentadas as três hipóteses em estudo, que demonstram o impacto dos construtos sobre o Desempenho de Mercado. Analisando os resultados obtidos, duas hipóteses obtiveram suporte estatístico para serem aceitas, sendo: $\mathrm{H}_{4}(\beta=0,635, p=0,039)$ e $H_{6}(\beta=0,357, p=0,024)$. Já a hipótese $H_{5}$ não foi suportada, sendo, portanto, rejeitada. As discussões ou reflexões dos resultados do teste de hipóteses são apresentadas mais adiante.

\subsection{COEFICIENTES DE DETERMINAÇÃO}

A função do coeficiente de determinação $\left(R^{2}\right)$ é informar a proporção da variância de uma variável dependente, a qual é justificada pelas variáveis independentes. Contudo, esse estudo afirma que o 42,7\% da variância do desempenho de mercado, a variável dependente, é explicada por suas variáveis independentes, que são: Novo Produto, Inovatividade e Capacidade Tecnológica. Para a variável Novo Produto, quando analisada como dependente, a variância apresentada é de $77 \%$ e é explicada por suas variáveis independentes, que são: Inovatividade e Capacidade Tenológica. Por sua vez, 56,3\% da Capacidade Tecnológica pode ser explicada pela Inovatividade da empresa. Os coeficientes de determinação $\left(R^{2}\right)$ do modelo teórico proposto estão apresentados na Tabela .

Tabela 5 - Coeficientes de Determinação do Modelo Teórico

\begin{tabular}{c|c}
\hline Variáveis Independentes & Coeficientes de Determinação $\left(\mathbf{R}^{\mathbf{2}}\right)$ \\
\hline CAP_TECN & 0,563 \\
\hline NOV_PROD & 0,770 \\
\hline DESEMP_MERC & 0,427 \\
\hline
\end{tabular}

Fonte: Dados provenientes da pesquisa. 


\subsection{ANÁLISE DOS RESULTADOS}

O modelo teórico proposto foi validado com base nas diretrizes gerais expostas, sem a necessidade de adequação dos construtos devido à identificação da qualidade dos ajustes (Goodnessof Fit - GOF), utilizando os índices $\chi 2 / g I$ (CMIN/DF), GFI, AGFI, RMSEA, NFI, TLI, CFI. Para a análise foi considerado a visão de Bagozzi e Yi (2012) em relação aos índices GFI e AGFI, onde ambos dependem do tamanho da amostra e as simulações mostram que ambos não funcionam bem como CMIN/DF, RMSEA, NFI e CFI.

Das seis hipóteses propostas nessa pesquisa, o teste estatístico suportou quatro, validando, desta forma, as hipóteses $\mathrm{H} 1, \mathrm{H} 3, \mathrm{H} 4$ e H6, já as demais, H2 e H5, não obtiveram nível de significância para serem suportadas pelo modelo estatístico. Os resultados suportados não são nenhuma novidade para a teoria: eles vão de encontro com os autores pesquisados e apresentados no referencial teórico. Todavia, as hipóteses não suportadas apresentam divergência de resultado em relação ao esperado.

As hipóteses $\mathrm{H}_{1}, \mathrm{H}_{3}$ e $\mathrm{H}_{5}$ tratam dos impactos positivos gerados pela inovatividade da empresa sobre o novo produto, a capacidade tecnológica e o desempenho de mercado, respectivamente. Para a hipótese $\mathrm{H}_{1}$, foi obtido suporte estatístico. $\mathrm{O}$ resultado se apresentou como esperado tal que a hipótese proposta é amplamente validade em âmbito teórico, onde, para Lumpkin e Dess (1996), há uma ligação entre inovatividade e novo produto. Isso mostra uma tendência da organização a participar e apoiar novas ideias, novidades, experimentação e processos criativos. Já Wang e Ahmed (2004) relacionam os temas através da capacidade de inovação global da organização que possui como dimensões inovatividade de produto.

A hipótese $\mathrm{H}_{3}$ também teve suporte estatístico: a revisão teórica apresenta evidências sobre o resultado alcançado, com base no entendimento que ambos os construtos possuem, como característica, o conhecimento, sendo a inovatividade entendida como um recurso da empresa que possibilita gerar novos conhecimentos. Por sua vez, o conhecimento gerado pode ser aproveitado pela empresa através da habilidade de utilizá-los e aplicá-los para gerir sistemas atuais e gerar mudanças, sendo tal habilidade a definição de capacidade tecnológica.

Cabe ressaltar que a hipótese $\mathrm{H} 5$ não foi suportada estatisticamente. Com esse resultado é recusada a hipótese que a inovatividade possui impacto positivo no desempenho de mercado. Todavia, a inovatividade possui um efeito indireto significativo sobre o desempenho, obtendo um erro padronizado na ordem de 0,856 , através do novo produto com um erro padronizado de 0,187 . Tal resultado estatístico também é possível de ser sustentado pelos autores pesquisados neste trabalho a partir da revisão da literatura.

No entanto, é possível observar que a influência positiva gerada pela inovatividade no desempenho da empresa, observada por Calantone, Cavusgil e Zhao (2002), possui como mediador o novo produto, tal que eles descrevem a inovatividade como um amplo processo de aprendizagem que permite a implementação de novas ideias, novos produtos ou novos processos. Em uma linha de pensamento semelhante, Wang e Ahmed (2004) observam a inovatividade como a capacidade de inserir novos produtos no mercado ou mesmo de abrir novos mercados, para assim obter melhor desempenho que seus concorrentes. Neste caso, pode ser proveniente da inovatividade, em novos produtos comercialmente bem-sucedidos.

Ainda é possível observar que o resultado estatístico que suporta $\mathrm{H}_{4}$ vai de encontro ao pensamento de Pavitt (1998), e também com a observação de Hall e Bagchi-Sen (2002), que com base em sua pesquisa, apresenta que a receita e as vendas, possuem relação significante com a introdução de novos produtos no mercado. Ainda segundo Tsai (2004), uma empresa que possui a possibilidade de ofertar um novo produto mais cedo que a da concorrência, devido a um processo de desenvolvimento mais acelerado, chegando primeiro 
no mercado pode garantir bons retornos econômicos. Portanto, como base nos resultados das hipóteses $\mathrm{H}_{4}$ e $\mathrm{H}_{5}$ e das análises dos pensamentos dos autores pesquisados, é possível observar que quando a inovatividade resulta em um novo produto, ela é capaz de gerar impacto positivo indireto sobre o desempenho de mercado, que por sua vez sofre impacto positivo direto gerado pelo novo produto.

As hipóteses $\mathrm{H}_{2}$ e $\mathrm{H}_{6}$ propõem que há um impacto positivo gerado pela capacidade tecnológica sobre o novo produto e sobre o desempenho de mercado, respectivamente. 0 resulta obtido de $\mathrm{H}_{2}$, que estatisticamente não suportou a hipótese, vai contra os achados de Hsu et al. (2014), que apresentam que a capacidade tecnológica se concentra em utilizar e aplicar conhecimentos e habilidades técnicas na criação de novos produtos e processos, bem como o descrito por Goedhuysa e Veugelersb (2012) ao enfatizar a complexidade do desenvolvimento de novos produtos que demandam domínio de novas tecnologias. 0 resultado em questão sugere que as empresas do segmento analisado não possuem a capacidade de impactar de forma positiva seus novos produtos através de sua capacidade tecnológica, mesmo esta, sendo segundo a média das respostas, superior a de seus concorrentes, atingindo 4,801 de média em uma escala do tipo Likert de sete pontos.

Por fim, a hipótese $\mathrm{H}_{6}$ foi suportada estatisticamente: esse resultado, conforme já mencionado, não é novidade para a teoria. Sua base parte do entendimento que as capacidades da empresa estão relacionadas à Visão Baseada em Recursos (RBV), consideras um recurso vital, que quando cultivado pelas empresas possibilitam alcançar um desempenho superior (BARNEY, 1991). Ao contrário de H2, para a hipótese H6, a empresa que utiliza a dimensão rotineira descrita por Figueiredo (2004), possui o conhecimento para manter os sistemas existentes em funcionamento, conforme descrito por Bell e Pavitt (1995). O resultado corrobora com os achados de Wilden e Gudergan (2015), que encontraram relação positiva entre a capacidade de marketing e tecnológica, e o desempenho das empresas.

Em relação ao poder de explicação, por meio do coeficiente de determinação $\left(R^{2}\right)$, este estudo obteve um percentual de $42,7 \%$ para o desempenho de mercado, que é a variável dependente explicada por suas variáveis independentes, que são: novo produto, inovatividade, e capacidade tecnológica. Tal valor é significativo quando observado que o desempenho de mercado é um construto complexo. Para o construto novo produto, quando analisado como dependente, o coeficiente atingido foi de $77 \%$ e é explicado por suas variáveis independentes, que são: inovatividade e capacidade tecnológica, sendo um percentual elevado de explicação, sendo que apenas houve validação da hipótese relacionada à inovatividade.

É possível descrever que a intenção de mudança, traduzida em geração de conhecimento, possui a capacidade de explicar tal percentual atingido de explicação de um novo produto. Já a relação entre a inovatividade e a capacidade tecnológica possui a capacidade de entregar um coeficiente de determinação de 0,563 , o que significa que $56,3 \%$ da capacidade tecnológica pode ser explicada por tal relação, o que se releva um alto valor se tratando de uma relação com apenas uma variável independente.

Para testar o efeito moderador da lucratividade $\left(\mathrm{H}_{7}\right)$ foi utilizado os procedimentos propostos por Hayes (2015) através do SPSS com a utilização do plot 14. Para todos os resultados, apresentados na Figura 2, foi utilizado um intervalo de confiança de $95 \%$ calculado por meio de 5.000 reamostragens no procedimento de bootstrapping. Foi constatado que $42 \%$ do desempenho de mercado pode ser explicado pelas suas variáveis moderadorasmediadoras. A lucratividade das organizações, foi medida a partir de uma escala de 5 pontos, sendo 1 (0 a 5\%), 2 (6\% a 10\%), 3 (11\% a 15\%), 4 (16\% a 20\%) e 5 (mais de $20 \%$ ). 
Assim, 55\% da amostra possui uma lucratividade inferior a $10 \%$ a escala foi transformada em variável dummy, sendo 0 para lucratividade até $10 \%$ e 1 para lucratividade superior a $10 \%$. Como pode ser observado na Figura 2, o desenvolvimento de novos produtos media a relação entre a inovatividade e desempenho de mercado, sendo que há um efeito indireto significativo a partir da moderação do nível de lucratividade (inferior e superior).

Cabe destacar que a relação entre o desenvolvimento de novos produtos e o desempenho de mercado é moderado pelo índice de lucratividade. Os resultados indicam que empresas com maior lucratividade apresentam uma relação mais forte e significativa entre estes dois construtos (Efeito 0,4477, $\mathrm{Cl}=0,2109$ a 0,6692) enquanto as empresas com menor índice de lucratividade não apresentam diferença significativa entre o desenvolvimento de novos produtos e o desempenho de mercado (Efeito 0,1833, $\mathrm{Cl}=-0,0579$ a 0,4344).

Os resultados dão suporte estatístico, confirmando, assim, a hipótese $\mathrm{H7}$. Ou seja, a capacidade de desenvolvimento de novos produtos, com níveis de lucratividade alta demostra um maior efeito direto sobre o desempenho de mercado. Esta relação parece ser clara que empresas que apresentam maior lucratividade investem mais em novos produtos e consequentemente apresentam um melhor desempenho no mercado.

Figura 2 - Papel Mediador do DNP e Moderador da Lucratividade

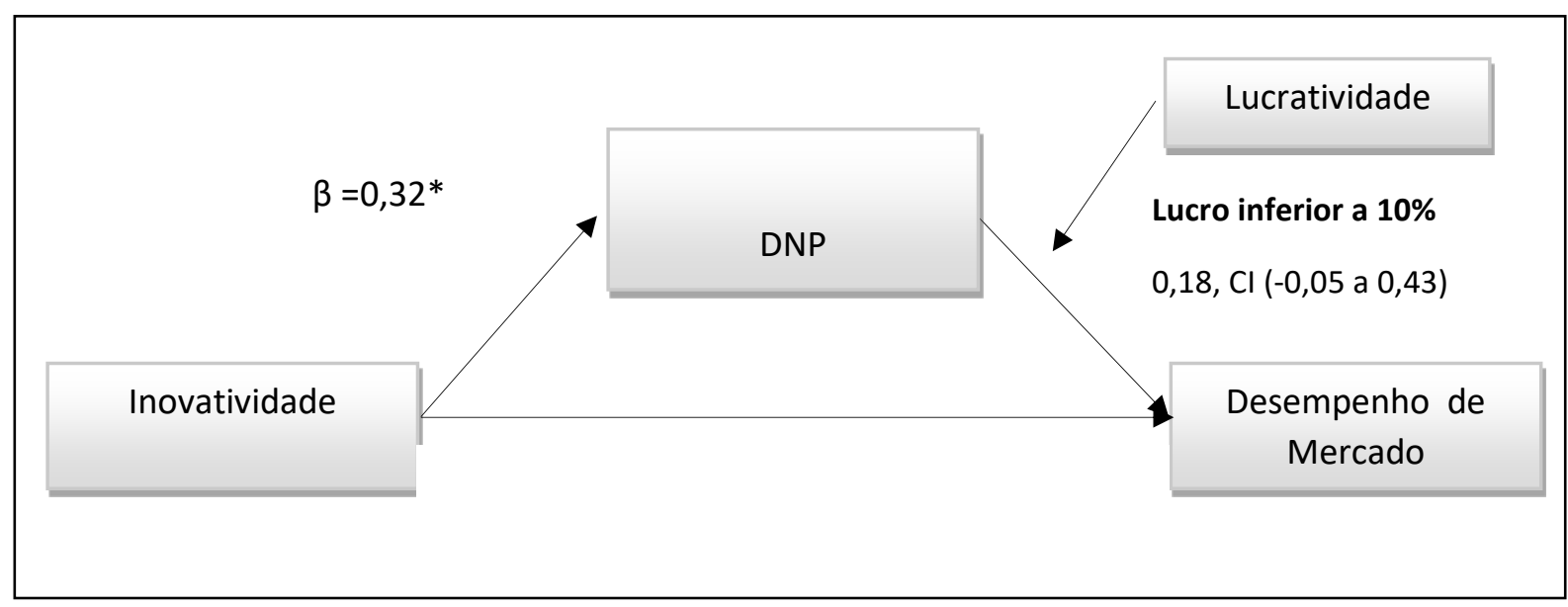

Obs.: ${ }^{*} p<0,01$.

Fonte: Dados provenientes da pesquisa.

Por fim, na última seção, apresentam-se as considerações finais. Nesta seção estão apresentadas as conclusões desta investigação. As contribuições de ordem teórica e de ordem gerencial, bem como as limitações encontradas no desenvolvimento deste estudo e as sugestões de pesquisas futuras.

\section{CONSIDERAÇÕES FINAIS}

Este estudo foi desenvolvido com base em teorias que se propõem a definir o novo produto, a inovatividade, a capacidade tecnológica e o desempenho de mercado. Esta investigação demonstrou que a inovatividade e a capacidade tecnológica das empresas do segmento metalmecânico das cidades de Caxias do Sul e de Bento Gonçalves, na Serra Gaúcha, que possuem relacionamento com o novo produto e com o desempenho de mercado, uma vez que interferem de forma direta ou indireta positivamente nas variáveis analisadas. Sendo assim, é possível dizer que a inovatividade das empresas que possui raízes históricas derivada da forma de ocupação da região e a capacidade tecnológica que é uma característica do segmento metalmecânico, podem possibilitar às empresas um melhor desempenho. 
Uma das finalidades desta pesquisa foi identificar quais os impactos que cada um dos construtos analisados tinha potencial de gerar sobre os demais. Sendo assim, com base no entendimento teórico reunido em cada um dos construtos, foi possível desenvolver um modelo que apresentou seis interações entre eles. Todas as interações encontradas na fase teórica foram positivas. Foi proposta nessa fase que: (i) a inovatividade possui impacto positivo no novo produto, na capacidade tecnológica e no desempenho de mercado das empresas; (ii) a capacidade tecnológica possui impacto positivo sobre o novo produto e sobre o desempenho de mercado; e, por fim, (iii) que o novo produto, ou o DNP, possui impacto positivo no desempenho de mercado das empresas.

Os resultados confirmam a validade discriminante, na medida em que as dimensões variâncias extraídas apresentam-se superiores às compartilhadas (FORNELL; LARCKER, 1981; CHURCHILL Jr., 1999). Os construtos novo produto e inovatividade apresentaram uma variância extraída baixa 0,503 e 0,432, respectivamente, quando o limite é 0,5. Por consequência, apresentaram novamente problemas na análise de validade discriminante.

Esta investigação apresenta contribuições de ordem teórica e gerencial. Dentre as contribuições de ordem teórica, destacam-se, a proposição e tese do modelo teórico com suas hipóteses de pesquisas. Mesmo não confirmando duas das hipóteses elas podem nos mostrar alguns ensinamentos importantes.

A primeira hipótese não suportada, evidencia que a inovatividade não impactou de forma direta e significativa no desempenho de mercado das organizações analisadas. No entanto, observa-se apesar da inovatividade não ter um efeito direto sobre o desempenho ele apresenta um efeito total significativo sobre o desempenho $(B=0,251 ; \mathrm{p}=0,000,95 \% \mathrm{Cl}=$ $0,460 \mid 1,429)$. Portanto, não é possível considerar a inovatividade como um construto dispensável para a melhoria do desempenho. A inovatividade é um construto importante para o desempenho de mercado das organizações mesmo não agindo de forma direta. 0 entendimento desse resultado está relacionado à definição de Menguc e Auh (2006), de que a inovatividade não é um fim, ou seja, o resultado realizado, mas um meio para atingi-lo, e aliada à visão de Lumpkin e Dess (1996), que ela é uma tendência da organização a participar e apoiar novas ideias.

A segunda hipótese que não teve confirmação foi a que se propôs testar o impacto positivo que a capacidade tecnológica gera no novo produto. Esse resultado contrariou em parte a teoria pesquisada, que deu suporte ao desenvolvimento da hipótese, como os autores Hsu et al. (2014) que escrevem que a capacidade tecnológica se concentra em utilizar habilidades técnicas na criação de novos produtos e processos, ou mesmo a visão de Goedhuysa e Veugelersb (2012), que a complexidade do desenvolvimento de novos produtos demandam domínio de novas tecnologias. Uma das justificativas que pode ser dada à não confirmação da $\mathrm{H}_{2}$ no presente estudo pode estar relacionado ao tipo de segmento estudado. Muitas das empresas pesquisadas são prestadoras de serviços que possuem uma boa capacidade tecnológica, no entanto uma baixa capacidade de geração de novos produtos, tendo em vista que neste segmento de prestação de serviço metalmecânico mais importante que gerar novos produtos é ter uma eficiência operacional.

Em relação à variância explicada, identificou-se que $42,7 \%$ de explicação dos três construtos para justificar o desempenho de mercado das empresas estudadas. Um resultado satisfatório dado que o desempenho em questão é um tema complexo que envolve várias dimensões para sua explicação total. Em relação à explicação de novo produto, foi encontrado um número expressivo, $77 \%$ pode ser explicado pelo modelo proposto, sendo que o único construto que apresentou impacto positivo sobre este foi a inovatividade. 
Além disso, em se tratando do poder de explicação, 56,3\% da capacidade tecnológica pode ser explicada pela inovatividade. A inovatividade, baseado no coeficiente de explicação do novo produto e da capacidade tecnológica, se demonstrou um tema que gera significativa influência positiva sobre tais construtos.

No que se refere aos testes do efeito da lucratividade sobre a relação entre o DNP Desenvolvimento de Novos Produtos e o desempenho de mercado $(\mathrm{H} 7)$, identificou-se que capacidade de desenvolvimento de novos produtos, com níveis de lucratividade alta demostra um maior efeito direto sobre o desempenho de mercado. Portanto, maiores índices de lucratividade tem um efeito mais significativo nesta relação.

No que tange às contribuições de ordem gerencial, este estudo apresentou elementos que colaboram na compreensão sobre o novo produto, a inovatividade, a capacidade tecnológica desempenho de mercado. A partir destas verificações sobre a relevância dos temas, é possível observar o quão fundamental é a inovatividade na organização, tal que gera impacto direto e indireto nos demais construtos estudados, e possibilita um percentual expressivo de explicação sobre o novo produto e a capacidade tecnológica.

Este estudo, então, possibilita que os gestores tenham um olhar mais holístico dos fatores que podem o impactar no desempenho das organizações. No caso desta pesquisa observa-se que a geração de novos produtos e a capacidade tecnológica impactam de forma direta e significativa no desempenho de mercado e a inovatividade, mesmo não tendo um impacto direto, mas de forma indireta influencia no desempenho. Os achados de pesquisa também revelam que a relação entre o desenvolvimento de novos produtos e o desempenho de mercado é mais forte para empresas que possuem uma margem de lucro maior. Portanto, manter uma margem de lucro adequada é uma condição indispensável para as organizações continuarem a investir em tecnologia, em inovação e consequentemente melhorar seu desempenho.

Por outro lado, este estudo se limitou à análise da busca de explicação do desempenho de mercado de uma empresa com base nos construtos novo produto, inovatividade, e capacidade tecnológica. Não foi procedida uma revisão bibliométrica da literatura que aceitaria reproduzir e ampliar o escopo da temática em questão, de modo que a pesquisa efetivada não é considerada abrangente e inclusiva, embora se admita a impossibilidade de envolver completamente o assunto delimitado pelo agrupamento do novo produto, da inovatividade, e da capacidade tecnológica, mesmo com uma ampla revisão bibliométrica. Pesquisas futuras podem desenvolver a mesma abordagem, adotando como base este estudo para definição dos critérios de inclusão e exclusão da pesquisa no conjunto de estudos conexos com determinado tema.

Uma limitação encontrada foi o resultado da validade discriminante que não atingiu o padrão descrito pela literatura para o construto novo produto e inovatividade, onde as variâncias extraídas se apresentaram inferiores às compartilhadas (FORNELL; LARCKER, 1981; CHURCHILL Jr., 1999). Para novos estudos, é sugerida a ampliação do número de questões para mensurar os construtos, a fim de elevar os resultados das variâncias extraídas, e, por conseguinte, atingir uma validade discriminante adequada para todos os temas analisados. Sugere-se, ainda, que seja desenvolvido um estudo qualitativo, a fim de investigar o motivo pelo qual duas hipóteses não foram confirmadas. Como sugestão de pesquisas futuras, indicase, também, aplicar este estudo em mais de um segmento industrial, tendo como finalidade a comparação dos resultados para distintos setores da economia, verificando se suas particularidades podem trazer algum impacto às relações hipotetizadas. 


\section{REFERÊNCIAS}

ARBUCKLE, J. L. Amos 18 user's guide. Chicago: SPSS, 2009.

BAGOZZI, R., YI, Y. Specification, evaluation, and interpretation of structural equation models. Journal of the Academy of Marketing Science, v. 40, n.1, p. 8-34, 2012. DOI: http://10.1007/s11747-011-0278-x.

BARNEY, J. B. Firm resources and sustained competitive advantage. Journal of Management, v. 17, n. 1, p. 99-120, 1991. DOI: http://dx.doi.org/10.1177/014920639101700108.

BELL, M.; PAVITT, K. The development of technological capabilities. In: BELL, R. Martin N. et al. Trade, technology and international competitiveness. Washington, DC: The World Bank, p. 69-101, 1995.

BEZERRA, C. A máquina de inovação: mentes e organizações na luta por diferenciação. Porto Alegre: Bookman, 2011.

BOEHE, D. M. ; DE TONI, D.; MILAN, G. S. Desempenho do processo de desenvolvimento de novos produtos: o peso relativo de fatores organizacionais, mercadológicos e operacionais. Revista de Administração (FEA-USP), v. 44, p. 250-264, 2009.

CALANTONE, R. J.; CAVUSGIL, S. T., ZHAO, Y. Learning orientation, firm innovation capability, and firm performance. Industrial Marketing Management, v. 31, n. 6, p. 515-524, 2002. DOI: http://10.1016 / S0019-8501 (01) 00203-6.

CHURCHILL Jr., G. Marketing research: methodological foundations. Orlando: Dryden Press, 1999.

COOPER, R. G. Benchmarking firms' new product performance and practice. Engineering Management Review, v.23, p.112-120, 1996.

COOPER, R. G.; EDGETT, S. J.; KLEINSCHMIDT, E. J. Benchmarking best NPD practices I. Research Technology Management, v.47, n.1, p.31-47, 2004. DOI: http:// https://doi.org/10.1080/08956308.2004.11671606.

CRAWFORD, C. M. New product management. $5^{\text {th }}$ edition. Burr Ridge: Irwin, 1997.

DAMANPOUR, F.; WISCHNEVSKY, J. D. An integration of research findings of effects of firm size and market competition on product and process innovations. British Journal of Management, v. 21, n. 4, p. 996-1010, 2010. DOI: https://doi.org/10.1111/j.14678551.2009.00628.x.

DARROCH, J. Knowledge management, innovation and firm performance. Journal of Knowledge Management, [S.I.], v. 9, n. 3, p. 101-115, 2005. DOI: http:// 10.12691/jbms-4-42. 
DE TONI, D.; MILAN, G. S. ; REGINATO, C. Fatores críticos para o sucesso no desempenho de novos produtos: um estudo aplicado ao setor moveleiro da Serra Gaúcha. Gestão \& Produção (UFSCAR. Impresso), v. 18, p. 587-602, 2011.

DE TONI, D.; MILAN, G. S.; SCHULER, M. As dimensões da imagem mercadológica. In: MILAN, G. S. (Org.) Administração mercadológica: teoria e pesquisas. Caxias do Sul: EDUCS, 2009.

DIBRELL, C.; CRAIG, J.; HANSEN, E. Natural environment, market orientation, and firm innovativeness: An organizational life cycle perspective. Journal of Small Business Management, v. 49, n. 3, p. 467-489, 2011. DOI: http://https://doi.org/10.1111/j.1540627X.2011.00333.x.

ENGELEN, A.; GUPTA, V.; STRENGER, L.; BRETTEL, M. Entrepreneurial orientation, firm performance, and the moderating role of transformational leadership behaviors. Journal of Management, v. 41, n. 4, p. 1069-1097, 2015. DOI:

https://doi.org/10.1177/0149206312455244.

FIGUEIREDO, P. N. Aprendizagem tecnológica e inovação industrial em economias emergentes: uma breve contribuição para o desenho e implementação de estudos empíricos e estratégias no Brasil. Revista Brasileira de Inovação, v. 3, n. 2, p. 323-361, 2004. DOI: https://doi.org/10.20396/rbi.v3i2.8648901.

FORNELL, C.; LARCKER, D. Evaluating structural equation models with unobservable variables and measurement error. Journal of Marketing Research, v. 18, p. 375-381, 1981. DOI: http://10.2307/3150979.

GANZER, P. P. Inovação de produto a partir dos processos de gestão do conhecimento e da inovatividade no setor têxtil 2016. 2017. Tese (Doutorado em Adminstração). Universidade de Caxias do Sul em associação ampla Pontifícia Universidade Católica do Rio Grande do Sul, Caxias do Sul, 2017.

GANZER, P. P.; RIBEIRO, D. S.; DA SILVA, E. R.; OLEA, P. M.; DORION, E. C. H.; NODARI, C. H.; DA SILVA, O. B.; PRODANOV, C. C. Inovação, inovatividade e gestão do conhecimento: um estudo de caso em uma indústria de grande porte no Rio Grande do Sul. Revista Espacios, v. 37, n. 1, 2016.

GOEDHUYSA, M.; VEUGELERSB, R. Innovation strategies, process and product innovations and growth: Firm-level evidence from Brazil. Structural Change and Economic Dynamics, v. 23, n. 4, p. 516-529, 2012. DOI: http://10.1016/j.strueco.2011.01.004.

GUAN, J.; YAM, R. C. M.; MOK, C. K.; MA, N. A study of the relationship between competitiveness and technological innovation capability based on DEA models. European Journal of Operational Research, v. 170, p. 971-986, 2006. DOI: http://10.1016/j.ejor.2004.07.054.

GUO, C.; WANG, Y.; HAO, A.; SARAN, A. Strategic positioning, timing of entry, and new product performance in business-to-business markets: do market-oriented firms make 
better decisions? Journal of Business-to-Business Marketing, 2018. DOI: https://doi.org/10.1080/1051712X.2018.1424690.

HAIR Jr. J. F.; BLACK, W. C.; BABIN, B. J.; ANDERSON, R. E.; TAHAM, R. L. Análise multivariada de dados. 6. ed. Porto Alegre: Bookman, 2009.

HALL, L.; BAGCHI-SEN, S. A study of R\&D, innovation, and business performance in the Canadian biotechnology industry. Technovation, v. 22, p. 231-244, 2002. DOI: http:// 10.1016/S0166-4972(01)00016-5.

HOMBURG, C.; JENSEN, O. The thought worlds of marketing and sales: which differences make a difference? Journal of Marketing, v. 71, n. 3, p. 124-142, 2007. DOI: http:// 10.1509/jmkg.71.3.124.

HSU, T. T.; TSAI, K. H.; HSIEH, M. H.; WANG, W. Y. Strategic orientation and new product performance: the roles of technological capability. Canadian Journal of Administrative Sciences/Revue Canadienne des Sciences de l'Administration, v. 31, n. 1, p. 44-58, 2014. DOI: https://doi.org/10.1002/cjas.1274.

KAGERMANN, H.; HELBIG, J.; HELLINGER, A.; WAHLSTER, W. Recommendations for implementing the strategic initiative INDUSTRIE 4.0: securing the future of German manufacturing industry; final report of the Industrie 4.0 Working Group. Forschungsunion, 2013.

KLINE, R. B. Principles and practice of structural equation modeling. $3^{\text {rd }}$ edition. New York: Guilford Press, 2011.

LALL, S. Technological capabilities and industrialization. World Development, v. 20, n. 2, p. 165-186, 1992. DOI: https://doi.org/10.1016/0305-750X(92)90097-F.

LUMPKIN, G. T.; DESS, G. G. Clarifying the entrepreneurial orientation construct and linking it to performance. Academy of Management Review, v. 21, 135-172. 1996. DOI:

http:10.2307/258632.

MENGUC, B.; AUH, S. Creating a firm-level dynamic capability through capitalizing on market orientation and innovativeness. Journal of the Academy of Marketing Science, v. 34, n. 1, p. 63-73, 2006. DOI: http:10.1177/0092070305281090.

PANIZZON, M. A influência da capacidade de aprendizado, da criatividade organizacional, da orientação empreendedora internacional, da capacidade tecnológica e da capacidade de reconfiguração na habilidade em desenvolvimento de novos produtos 2016. 2017. Tese (Doutorado em Administração). Universidade de Caxias do Sul em associação ampla Pontifícia Universidade Católica do Rio Grande do Sul, Caxias do Sul, 2017.

PAVITT, K. Technologies, products and organization in the innovating firm: what Adam Smith tells us and Joseph Schumpeter doesn't. Industrial and Corporate Change, v. 7, n. 3, p. 433452, 1998. 
PFEFFER, J. Changing mental models: Hr's most important task. Human Resource Management, v. 44, n. 2, p. 123-128, 2005. DOI: http:10.1002/hrm.20053.

POSADA, J.; TORO, C.; BARANDIARAN, I.; OYARZUN, D.; STRICKER, D.; DE AMICIS, R.; VALLARINO, I. Visual computing as a key enabling technology for industrie 4.0 and industrial internet. IEEE computer graphics and applications, v. 35, n. 2, p. 26-40, 2015. DOI: http://10.1109/MCG.2015.45.

POTERALSKI, J. Support for the innovativeness of polish economy quoting the example of innovative economy operational programme". Transformations in Business \& Economics, v. 10, n. 2A. (23A), p. 345-356, 2011.

RUBERA, G.; KIRCA, A. H. Firm innovativeness and its performance outcomes: a metaanalytic review and theoretical integration. Journal of Marketing, v. 76, n. 3, p. 130-147, 2012. DOI: http:10.2307/41714493.

ROGERS, E. M. Diffusion of innovations. $5^{\text {th }}$ edition. New York: Free Press, 2003. SHENG, S.; ZHOU, K. Z.; LESSASSY, L. NPD speed vs. innovativeness: the contingent impact of institutional and market environments. Journal of Business Research, v. 66, n. 11, p. 2.3552.362, 2013. DOI: http://10.1016/j.jbusres.2012.04.018.

SONG, X. M.; PARRY, M. E. A cross-national comparative study of new product development processes: Japan and United States. Journal of Marketing, v. 61, n. 2, p. 1-19, 1997. DOI: http://dx.doi.org/10.2307/1251827.

SPANOS, Y. E.; LIOUKAS, S. An examination into the causal logic of rent generation: contrasting Porter's competitive strategy framework and the resource-based perspective. Strategic Management Journal, v. 22, n. 10, p. 907-934, 2001. DOI: http:10.1002/smj.174.

SUBRAMANIAN, A. Innovativeness: redefining the concept. Journal of Engineering and Technology Management. v. 13, n. 3-4, p. 223-243, 1996. DOI: https://doi.org/10.1016/S0923-4748(96)01007-7.

TAKAHASHI, S.; TAKAHASHI, V. P. Gestão de inovação de produtos: estratégia, processo, organização e conhecimento. Rio de Janeiro: Elsevier, 2007.

TEECE, D.; PISANO, G.; SHUEN, A. Dynamic capabilities and strategic management. Strategic Management Journal, v. 18, n. 7, p. 509-542, 1997. DOI: https://doi.org/10.1002/(SICI)10970266(199708)18:7<509::AID-SMJ882>3.0.CO;2-Z.

TIDD, J.; BODLEY, K. The influence of project novelty on the new product development process. R\&D Management, v. 32, n. 2, p.127-138, 2002. DOI: http: 10.1111/14679310.00245 .

TSAI, K. The impact of technological capability on firm performance in Taiwan's electronics industry. Journal of High Technology Management Research, v. 15, p. 183-195, 2004. DOI: http: 10.1016/j.hitech.2004.03.002. 
TZOKAS, N.; KIM, Y. A.; AKBAR, H. Absorptive capacity and performance: the role of customer relationship and technological capabilities in high-tech SMEs. Industrial Marketing Management, v. 47, p. 134-142, 2015. DOI: http: 10.1016/j.indmarman.2015.02.033

VENKATRAMAN, N.; RAMANUJAM, V. Measurement of business performance in strategy research: A comparison of approaches. Academy of Management Review, v. 11, n. 4, p. 801814, 1986. DOI: http://10.2307/258398.

VERGANTI, R.; ÖBERG, Å. Interpreting and envisioning - a hermeneutic framework to look at radical innovation of meanings. Industrial Marketing Management, v. 42, n. 1, p. 86-95, 2013. DOI: http://dx.doi.org/10.1016/j.indmarman.2012.11.012.

VERONA, G. A resource-based view of product development. The Academy of Management Review, v. 24, n. 1, p. 132-142, 1999. DOI: https://doi.org/10.5465/amr.1999.1580445.

WANG, C. L.; AHMED, P. K. The development and validation of the organisational innovativeness constructo using confirmatory factor analysis. European Journal of Innovation Management, v. 7, n. 4, p. 303-313, 2004. DOI:

https://doi.org/10.1108/14601060410565056.

WILDEN, R.; GUDERGAN, S. P. The impact of dynamic capabilities on operational marketing and technological capabilities: investigating the role of environmental turbulence. Journal of the Academy of Marketing Science, v. 43, n. 2, p. 181-199, 2015. DOI:

https://doi.org/10.1007/s11747-014-0380-y.

ZOOGAH, D. B. High-performance organizing, environmental management, and organizational performance: an evolutionary economics perspective. Human Resource Management, v. 57, n. 1, p. 159-175, 2018. DOI:

https://doi.org/10.1002/hrm.21869. 
APÊNDICE A - Instrumento de Coleta de Dados NOVO PRODUTO

1. Nossa empresa apresenta com frequência novas linhas de produtos e serviços.

2. Nossa empresa frequentemente acrescenta novos produtos ou serviços ao catálogo existente.

3. Nossa empresa frequentemente aperfeiçoa ou revisa os produtos ou serviços existentes.

4. Nossa empresa frequentemente muda os produtos ou serviços a fim de reduzir custos.

Darroch

(2005)

5. Nossa empresa frequentemente reposiciona os produtos ou serviços existentes.

6. Os produtos lançados pela empresa são novos para o mundo.

7. Os produtos lançados pela empresa são novos para a empresa.

8. A empresa reposiciona produtos existentes.

\section{INOVATIVIDADE}

9. Nossa empresa experimenta novas ideias com frequência.

10. Nossa empresa busca novas maneiras de fazer as coisas.

11. Nossa empresa geralmente é a primeira a colocar no mercado novos produtos e serviços.

12- Nossa empresa entende a inovação como algo arriscado demais.

13- Em nossa empresa, a introdução de novos produtos tem crescido nos últimos cinco anos.

14. Nossos novos produtos e/ou novos serviços geralmente são vistos pelos clientes como muito originais.

15. Em comparação aos nossos concorrentes, nossa empresa tem apresentado mais produtos e serviços inovadores nos últimos cinco anos.

16. Em comparação aos concorrentes, nossa empresa tem uma taxa de sucesso menor quanto ao lançamento de produtos e serviços.

\section{CAPACIDADE TECNOLÓGICA}

17. A empresa tem maior capacidade que os principais concorrentes em adquirir tecnologias relevantes.

18. A empresa tem maior capacidade que os principais concorrentes em identificar novas oportunidades tecnológicas.

19. A empresa tem maior capacidade que os principais concorrentes em responder às mudanças tecnológicas.

20. A empresa tem maior capacidade que os principais concorrentes em dominar tecnologias-chave de seu setor de atuação.

DESEMPENHO DE MERCADO (considerando os últimos 12 meses)

21. Aquisição de novos clientes.

22. Aumento das vendas a clientes atuais.

23. Crescimento das receitas totais de vendas.

24. Poder de precificação no mercado.

25. Rentabilidade da unidade de negócios.

26. Retorno sobre as vendas (ROS - Return on Sales).

Tzokas,

Kim e

Akbar

(2015)

Calantone,

Cavusgil e

Zhao

(2002) e

Wang e

Ahmed

(2004)

Pfeffer

(2005) e

De Toni,

Milan e

Schuler

(2009) 